\title{
A Comparison of Thermal Growing Season Indices for the Northern China during 1961-2015
}

\author{
Linli Cui, ${ }^{1,2}$ Jun Shi, ${ }^{2,3}$ and Yue $\mathrm{Ma}^{3}$ \\ ${ }^{1}$ Shanghai Satellite Remote-Sensing and Application Centre, Shanghai 200030, China \\ ${ }^{2}$ Shanghai Key Laboratory of Meteorology and Health, Shanghai 200030, China \\ ${ }^{3}$ Shanghai Climate Center, Shanghai Meteorological Bureau, Shanghai 200030, China \\ Correspondence should be addressed to Linli Cui; cllcontact@163.com
}

Received 26 February 2017; Revised 20 May 2017; Accepted 28 May 2017; Published 27 July 2017

Academic Editor: Nir Y. Krakauer

Copyright (C) 2017 Linli Cui et al. This is an open access article distributed under the Creative Commons Attribution License, which permits unrestricted use, distribution, and reproduction in any medium, provided the original work is properly cited.

\begin{abstract}
Vegetation phenology is one of the most direct and sensitive indicators of terrestrial ecosystem in response to climate change. Based on daily mean air temperature at 877 meteorological stations over northern China from 1961 to 2015, the correlations and differences for different definitions of the growing season parameters (start, end, and length of the growing season) were investigated, and results show that higher correlations of $0.81-0.93$ are found when indices which do not consider frost are compared with those of the same length which include the frost criteria, and lower correlations of 0.63-0.79 are observed when the length of indices is different and one of the indices includes the frost criteria or EI $3\left(10 \mathrm{~d}<5^{\circ} \mathrm{C}\right)$ is included. Lower correlations and larger differences are generally observed in the eastern and northwestern parts while higher correlation and smaller difference appeared in the northeastern and southwestern parts of northern China; thus the applicability comparison and selection of different definitions have important influence on the identifying and counting of the timing and length of the growing season in the eastern and northwestern regions of northern China.
\end{abstract}

\section{Introduction}

The global-mean surface temperature has increased by a linear trend of $0.85[0.65-1.06]^{\circ} \mathrm{C}$ from 1880 to 2012 , and the increase in surface temperature during 2081-2100 is projected to likely be $0.3-4.8^{\circ} \mathrm{C}$ relative to $1986-2005$ [1]. Changes in the vegetation growing season have received much attention as the timing and length of the growing season are sensitive to climate variation and global warming $[2,3]$, and changes in the growing season can also affect the function and service of ecosystems (e.g., agricultural production, carbon sequestration potential, soil and water conservation, and biological diversity) and global and regional climate [4-6]. An increasing number of studies, based on climatological, phonological, and satellite remote sensing data, have reported an earlier spring, later autumn, and consequently prolonged growing season over most of the Northern Hemisphere in the twentieth century $[1,6]$, though the earlier onset of the growing season was slowed down in the first decade of the twenty-first century [3]. A research from Barichivich et al. [4] showed that the potential thermal growing season had been extended by 10.5 days at high northern latitudes during 1982-2011, and the overall lengthening of the growing season in the Eurasian region (12.6 days, $P<0.01)$ was more prominent than that in North America (6.2 days, $P>0.05$ ). Therefore, researching into the changes of growing season has become one of the most important scientific issues in studies of global climate change and terrestrial ecosystems $[5,7]$.

The thermal growing season is a span of time within which plants can theoretically grow; in other words, the constraints of air temperature on plant growth are released during this time and consequently growth can take place if other environmental needs are satisfied $[8,9]$. It is generally counted as the number of days when air temperature exceeds a predefined threshold [7, 9, 10]. Many studies have examined the changes or trends of thermal growing season in regional or global scale; for example, Frich et al. [11] found that the thermal growing season was prolonged 


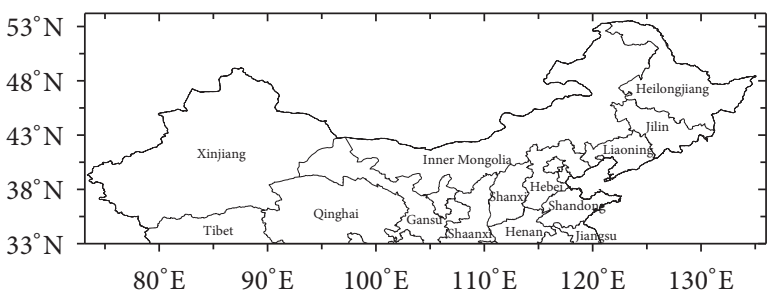

(a)

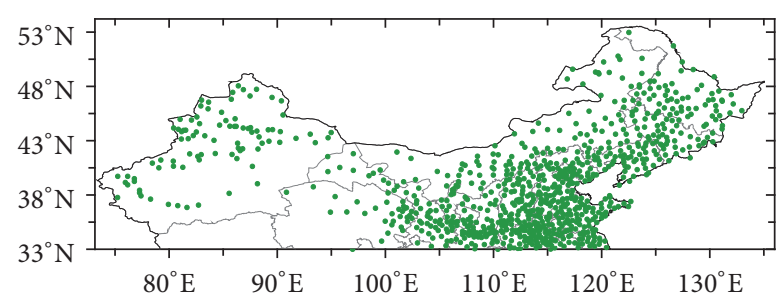

(b)

FIGURE 1: The administrative division (a) and spatial distribution of selected meteorological stations (b) in northern China.

significantly throughout the major mid-latitude regions in the Northern Hemisphere during the second half of the twentieth century. Walther and Linderholm [9] showed that the thermal growing season had an earlier start of 12 days, a later end of 8 days, and hence an extension of about 20 days over the Greater Baltic Area in the twentieth century. Song et al. [12] indicated that the thermal growing season had been extended by 2.3 days per decade in northern China and 1.3 days per decade in southern China averagely during 1951-2007. Guo et al. [7] showed that the tree growing season had an earlier onset of 9.0 and 11.1 days and a later end of 4.8 and 5.8 days, with an extension of 13.3 and 16.4 days during 1961-2013 in the Hebei and Shanxi mountainous region and Loess Plateau region, respectively. In Xinjiang, China, Ci et al. [6] suggested that the growing season was extended about 2.5 days per decade during 1961-2010.

However, few studies have conducted a comparative analysis of the homogeneity and difference of different definitions used to calculate the thermal growing season in one or more specific areas. Walther and Linderholm [9] examined the correlation and difference of a number of definitions and found that including the frost criterion or not had important effects on the start of the growing season in the western maritime parts of the Greater Baltic Area, whereas frost did not have the same influence on the end of the growing season. Song et al. [12] used the same definitions to analyze the trends in the growing season parameters (start, end, and length of the growing season) in China and showed that all five indices could be applied to northern China, but only two indices without regard to the frost criteria were suitable for the stations in southern China. The relationship between climate and the growing season is various in different regions, and there is no worldwide definition which can be widely applicable to all regions to build the thermal growing season parameters $[9,13]$. On the other hand, different definitions of the growing season parameters may reflect the climate change in different ways, and even small changes in the index definitions may bring about heterogeneous results in a specific region [9]. In different parts of China, changes in the growing season parameters have different amplitudes with various index definitions $[12,14,15]$, but up to now few studies have carried out an in-depth research.

This work is aimed at comparing the different definitions of growing season parameters over northern China, based on daily mean air temperature data at 877 stations during 1961-2015. The paper is organized as follows. Section 2 describes the datasets and processing methods used in this study. The correlation and difference between different definitions of thermal growing season parameters are presented in Section 3. Discussion and conclusions are given in Sections 4 and 5, respectively.

\section{Data and Methods}

2.1. Data. Daily mean air temperature data from the National Meteorological Information Center, China Meteorological Administration were utilized to calculate each type of growing season parameters (start, end, and length of the growing season). There are totally 1218 observation stations over northern China with the span of time from 1951 to 2015, and quality control of data was conducted before release by the departure accumulating method. Before 1961, the observation data had higher missing rate and the number of stations was less, so only those stations with long-time average missing rate of less than $1 \%$ in the whole year, spring, and autumn, respectively, during 1961-2015 were included in our study. Finally, 877 out of 1218 stations were selected (Figure 1). In the southeastern part of the study area, including Hebei, Shandong, Shanxi, Henan, Shaanxi, southern Gansu, northern Jiangsu, and Anhui, stations are dense, while in the western and northern parts, including Xinjiang, northern Tibet, Qinghai, northern Gansu, Inner Mongolia, and northern Heilongjiang, stations are sparse and unevenly distributed. The missing data from a single day was filled in by the average of two adjacent days before and after in the same station, and the missing data from two or more continuous days were filled with the simple linear regression method, based on the observation data of neighboring stations which had the strongest correlation and had no missing data at the same time.

2.2. Method. Based on daily mean temperature data, fifteen indices of the growing season parameters, including four indices of the start of growing season (SI), five indices of the end of growing season (EI), and six indices of the length of growing season (LI), were calculated according to the definitions in Table 1. In middle and higher latitudes, the threshold of $5^{\circ} \mathrm{C}$ daily mean temperature was widely accepted to determine the thermal growing season $[7-12,16]$. Chen [14] also found there was a significant correlation between the length of the growing season based on phenology and the temperature of no less than $5^{\circ} \mathrm{C}$ in the Taunus Mountain 


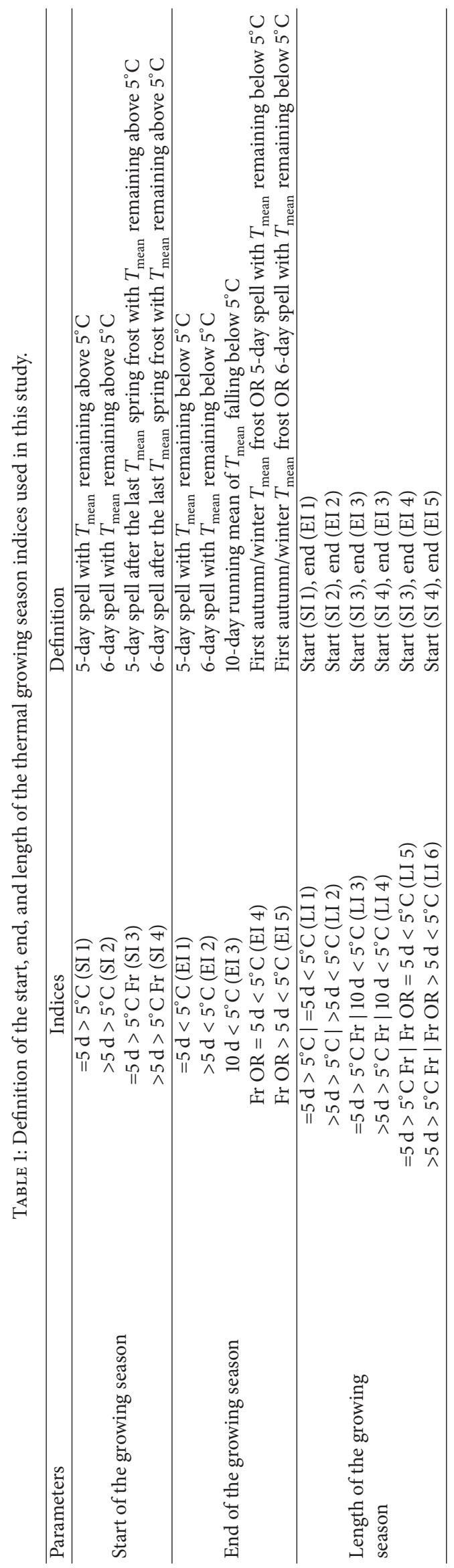


TABLE 2: Pearson's correlation coefficient $(r)$ for combination of the start indices of the growing season. Single bold values show the mean coefficients over northern China, and the paired values below show the minimum (left) and maximum (right) coefficients.

\begin{tabular}{|c|c|c|c|c|c|c|}
\hline Start of GS & & & & & & \\
\hline \multirow{2}{*}{$=5 \mathrm{~d}>5^{\circ} \mathrm{C}(\mathrm{SI} 1)$} & \multicolumn{2}{|c|}{0.85} & \multicolumn{2}{|c|}{0.89} & \multicolumn{2}{|c|}{0.79} \\
\hline & 0.56 & 0.99 & 0.37 & 1.00 & 0.34 & 0.97 \\
\hline \multirow{2}{*}{$>5 \mathrm{~d}>5^{\circ} \mathrm{C}(\mathrm{SI} 2)$} & \multirow{2}{*}{\multicolumn{2}{|c|}{-}} & \multicolumn{2}{|c|}{0.79} & \multicolumn{2}{|c|}{0.93} \\
\hline & & & 0.39 & 0.97 & 0.57 & 1.00 \\
\hline \multirow{2}{*}{$=5 \mathrm{~d}>5^{\circ} \mathrm{C} \mathrm{Fr}(\mathrm{SI} 3)$} & \multirow{2}{*}{\multicolumn{2}{|c|}{-}} & \multirow{2}{*}{\multicolumn{2}{|c|}{ - }} & \multicolumn{2}{|c|}{0.88} \\
\hline & & & & & 0.61 & 1.00 \\
\hline
\end{tabular}

Note. $r \geq 0.26$, correlation is significant at the 0.05 level; $r \geq 0.34$, correlation is significant at the 0.01 level; $r \geq 0.43$, correlation is significant at the 0.001 level. The same as in Tables 3 and 4 and Figures 2, 4, and 6.

area, but no significant correlation existed between the length of the growing season and temperature of no less than $10^{\circ} \mathrm{C}$. Consequently, in all of the definitions, the threshold of $5^{\circ} \mathrm{C}$ daily mean temperature was used, and the main difference between definitions was that the length of the spells with daily mean temperature remaining above $5^{\circ} \mathrm{C}$ (start) or below $5^{\circ} \mathrm{C}$ (end).

2.2.1. The Definitions of the Start of Thermal Growing Season. For indices of growing season start, SI $1\left(=5 \mathrm{~d}>5^{\circ} \mathrm{C}\right)$ and SI $2\left(>5 \mathrm{~d}>5^{\circ} \mathrm{C}\right)$ were defined as the first 5-day and 6-day spells, respectively, with daily mean temperature remaining above $5^{\circ} \mathrm{C}$, according to Carter [8] and Frich et al. [11]. The appearance of last spring frost was considered in the definition of SI $3\left(=5 \mathrm{~d}>5^{\circ} \mathrm{C} \mathrm{Fr}\right)$ and SI $4\left(>5 \mathrm{~d}>5^{\circ} \mathrm{C} \mathrm{Fr}\right)$. SI 3 and SI 4 were defined as the 5-day and 6-day spell, respectively, with daily mean temperature remaining above $5^{\circ} \mathrm{C}$ after the last spring frost, which were used by Jones et al. [10] and Walther and Linderholm [9].

\subsubsection{The Definitions of the End of Thermal Growing Season.} The definitions of the end of growing season were corresponding to those of the start to some extent. EI 1 ( $=5 \mathrm{~d}<$ $\left.5^{\circ} \mathrm{C}\right)$ and EI $2\left(>5 \mathrm{~d}<5^{\circ} \mathrm{C}\right)$ were defined as the first 5-day and 6-day spells, respectively, with daily mean temperature remaining below $5^{\circ} \mathrm{C}[11,16]$. In accordance with Carter [8], EI $3\left(10 \mathrm{~d}<5^{\circ} \mathrm{C}\right)$ was the first 10 -day running mean of daily mean temperature falling below $5^{\circ} \mathrm{C}$. The first autumn/winter frost from daily mean temperature or the first 5-day spell with daily mean temperature below $5^{\circ} \mathrm{C}$ was used in the definition of EI $4\left(\right.$ Fr OR $\left.=5 \mathrm{~d}<5^{\circ} \mathrm{C}\right)[9]$, and EI $5\left(\right.$ Fr OR $\left.>5 \mathrm{~d}<5^{\circ} \mathrm{C}\right)$ was defined here as the first autumn/winter frost or the first 6 -day spell with daily mean temperature below the threshold.

2.2.3. The Definitions of the Length of Thermal Growing Season. Combining the start and end indices, six different indices of the growing season length were obtained. LI 1 ( $=5 \mathrm{~d}$ $>5^{\circ} \mathrm{Cl}=5 \mathrm{~d}<5^{\circ} \mathrm{C}$ ) was the combinations of SI 1 and EI 1 [16], and LI $2\left(>5 \mathrm{~d}>5^{\circ} \mathrm{C} \mid>5 \mathrm{~d}<5^{\circ} \mathrm{C}\right)$ was the combination of SI 2 and EI 2 [11]. For LI $3\left(=5 \mathrm{~d}>5^{\circ} \mathrm{C} \mathrm{Fr} \mid 10 \mathrm{~d}<5^{\circ} \mathrm{C}\right)$ and LI $4\left(>5 \mathrm{~d}>5^{\circ} \mathrm{C} \mathrm{Fr} \mid 10 \mathrm{~d}<5^{\circ} \mathrm{C}\right)$, two start indices considering the occurrence of spring frost (SI 3 and SI 4) and one end index of EI 3 were grouped, respectively, which were used by Walther and Linderholm [9]. For LI $5\left(=5 \mathrm{~d}>5^{\circ} \mathrm{C}\right.$ Fr $\mid$ Fr OR $\left.=5 \mathrm{~d}<5^{\circ} \mathrm{C}\right)$ and LI $6\left(>5 \mathrm{~d}>5^{\circ} \mathrm{C} \mathrm{Fr} \mid\right.$ Fr OR $\left.>5 \mathrm{~d}<5^{\circ} \mathrm{C}\right)$, the occurrence of frost was taken into account in both the start indices and the end indices. LI 5 was the combination of SI 3 and EI 4 [9], and LI 6 was defined here as the combination of SI 4 and EI 5.

2.2.4. Correlation and Difference Analysis. To compare the homogeneity and the difference of different definitions, correlation analysis was performed for indices in each type of growing season parameters using the Pearson correlation coefficient $(r)$ and the statistical significance was tested according to the coefficient value and the number of samples $(n=55)$. The mean correlation coefficient over northern China was calculated using the station-averaged method, and the minimum and maximum coefficients were selected directly from the 877 stations, respectively, and had one value for each combination. The mean and maximum differences between indices were also calculated at each station based on the 55-year differential data sequence, and the difference was further tested for statistical significance at the 0.01 confidence level using a two-tailed $t$-test. Kriging interpolation method was used to produce the spatial patterns of correlation and difference of growing season indices based on the latitude and longitude of each station, and the results were showed with Golden Software Surfer. Considering the sparse distribution of stations in most areas of western China and some areas of northeastern China, the interpolation results may not be able to reflect the real characteristics in these areas.

\section{Results}

\subsection{Indices for the Start of the Growing Season}

3.1.1. Regional Average of Correlation for Combinations of Indices. The correlation coefficients for the indices of the growing season start in the whole study are listed in Table 2. For the mean correlation coefficient, the highest value $(r=$ 0.93) was obtained from the combination of SI 2 and SI 4 , and the lowest value $(r=0.79)$ was acquired from the combinations of SI 1 and SI 4 and SI 2 and SI 3. The maximum correlation coefficients among combinations of indices ranged from 0.97 to 1.00 , the mean correlation coefficients ranged from 0.79 to 0.93 , and the minimum correlation coefficients ranged from 0.34 to 0.61 . The weaker correlations 


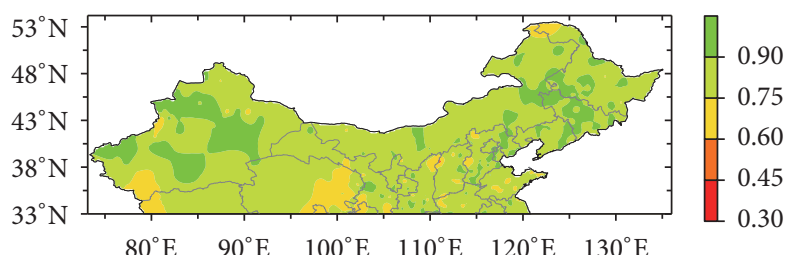

(a) SI 1 versus SI 2

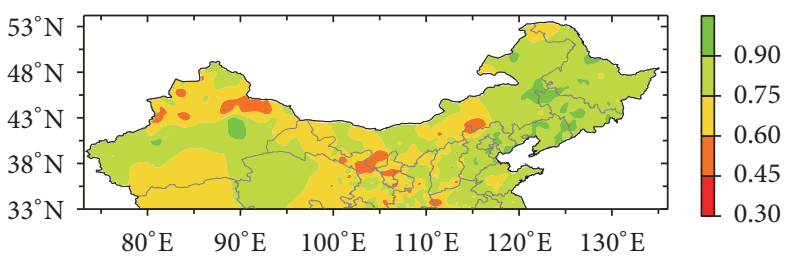

(c) SI 2 versus SI 3

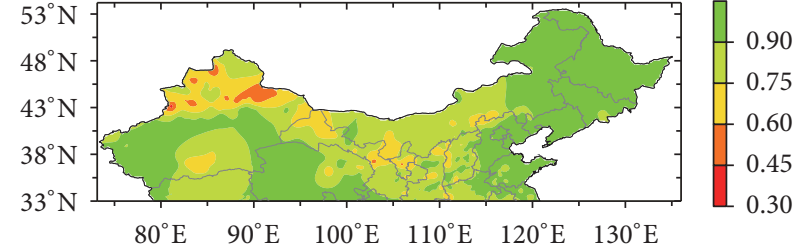

(b) SI 1 versus SI 3

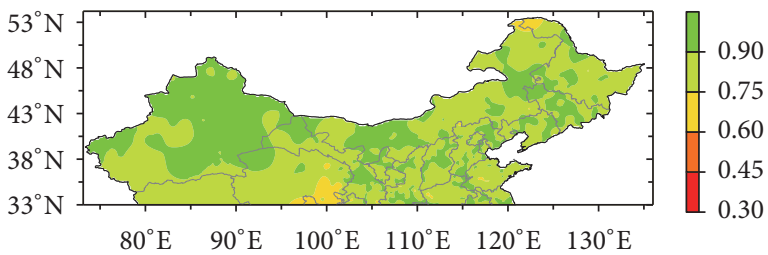

(d) SI 3 versus SI 4

FIGURE 2: Correlation coefficients for combinations of the start indices of growing season in northern China.

were found when the length of the spells exceeding the threshold was different and one of the indices included the frost criteria (e.g., mean correlation was equal to 0.79 at SI 1 versus SI 4 or SI 2 versus SI 3). The higher correlation coefficients were found when indices without regard for frost were compared with those including the frost criteria and both had the same length of the spells (e.g., mean correlation was equal to 0.89 at SI 1 versus SI 3). If only the lengths of the spells exceeding the thresholds were different among combinations of indices, correlation coefficients were medium (e.g., mean correlation was equal to 0.85 at SI 1 versus SI 2).

3.1.2. Spatial Distribution of Correlation for Combinations of Indices. The correlations of the growing season start were spatially differentiated and were statistically significant at the 0.01 level in all regions of northern China. Stations with higher correlation coefficients among combinations of indices were consistently located in the northeastern part of the study area, whereas in the western parts, there was no constant and strong relationship between different indices (Figure 2). The correlation coefficients for the combination of SI 1 and SI 2 were all over 0.55, and at most of stations they ranged from 0.75 to 0.90 , accounting for $67.3 \%$ of the total stations across northern China (Figure 2(a)). In some areas in northeastern China, Xinjiang, Hebei, Shanxi, Shaanxi, and Gansu, correlation coefficients were over 0.90. For the combination of SI 1 and SI 3, higher correlation coefficients of more than 0.90 mainly occurred in northeastern China, most of Hebei and Shandong, western and southern Qinghai, and some areas of southwestern and southeastern Xinjiang, accounting for $63.6 \%$ of the total stations across northern China (Figure 2(b)). A similar spatial pattern in correlation coefficients also existed at SI 2 versus SI 4. The correlation coefficients for SI 2 versus SI 3 were generally lower, and at most stations they ranged from 0.60 to 0.90 , accounting for $83.8 \%$ of the total stations (Figure 2(c)). The spatial distribution of correlation coefficients for SI 1 versus SI 4 was basically similar to that of SI 2 versus SI 3. The correlation coefficients for SI 3 versus SI 4 were all over 0.60 , and at the vast majority of stations they ranged from 0.75 to 1.00 , accounting for $96.8 \%$ of the total stations; especially in most areas of northern and eastern Xinjiang, they were all over 0.90 (Figure 2(d)).

3.1.3. Spatial Distribution of Difference for Combinations of Indices. The differences in the start of the growing season were also spatially differentiated, with smaller mean and maximum differences in the northeastern and western parts and larger values in the central and eastern parts of the study area (Figure 3 ), and the differences were statistically insignificant at almost all the stations for four combinations of indices. For the two combinations of SI 1 versus SI 3 and SI 2 versus SI 4, larger mean and maximum differences were observed in the eastern and northwestern parts, with the mean values of 2.0-5.0 days and the maximum values of 20-50 days at most stations, while smaller differences were found in the northeastern and southwestern parts of the study area, with the mean of $0-2.0$ days and the maximum of $0-40$ days (Figures $3(a)-3(d)$ ). So the consideration of spring frost seems to be less important for parts of the study area regarding the mean differences.

For combinations of SI 1 versus SI 2 and SI 3 versus SI 4 , both the mean and the maximum differences were larger than those of SI 1 versus SI 3 and SI 2 versus SI 4 as a whole. The mean differences for SI 1 versus SI 2 mainly ranged from 2.0 to 5.0 days, accounting for $94.5 \%$ of the total stations across northern China, and larger differences were mainly distributed in the southeastern part of the study area, with the mean of 3.5-6.5 days (Figure 3(e)). For the maximum differences, larger values of 30-53 days were distributed in some scattered areas, whereas smaller differences of 0-20 days appeared in some areas in the northeastern and western parts of the study area (Figure 3(f)). The mean differences for combination of S3 and SI 4 were smaller (0-2.0 days) in some areas in Xinjiang, Gansu, and Inner Mongolia and some little areas in Heilongjiang, Jilin, Liaoning, Hebei, Shanxi, and Ningxia, but in other areas they were larger with the values of 


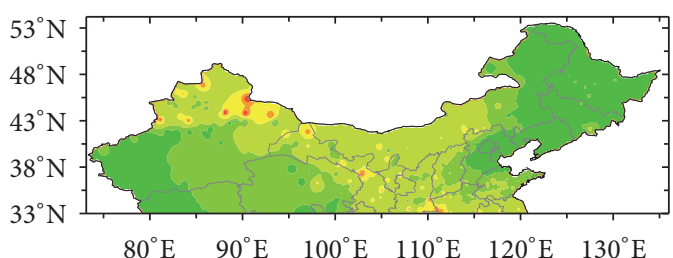

(a) Mean SI 3-SI 1

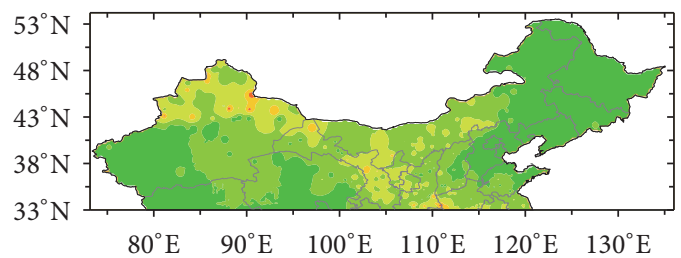

(c) Mean SI 4-SI 2

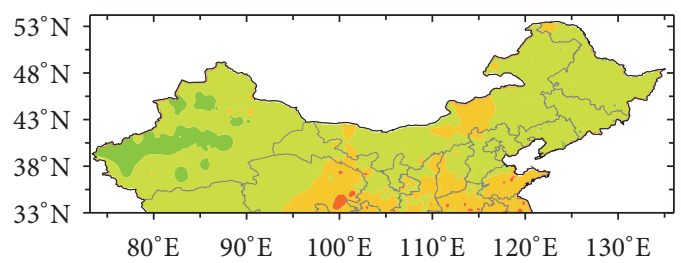

(e) Mean SI 2-SI 1

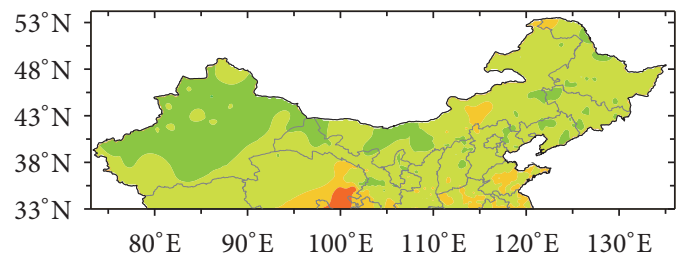

(g) Mean SI 4-SI 3

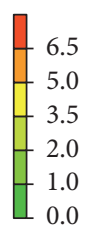

5.0

3.5

.0

$33^{\circ} \mathrm{N}$

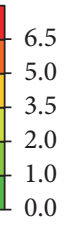

$$
\begin{aligned}
& 6.5 \\
& 5.0 \\
& 3.5 \\
& 2.0 \\
& 1.0 \\
& 0.0
\end{aligned}
$$
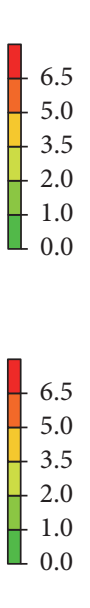

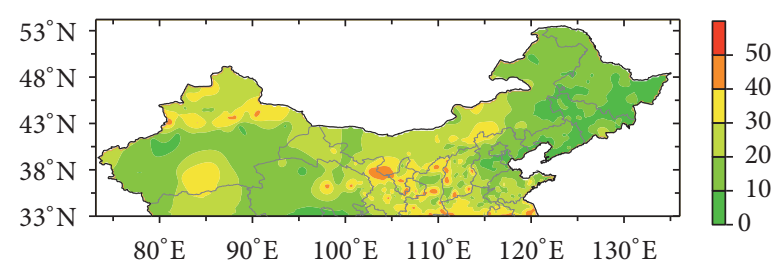

(b) Maximum SI 3-SI 1

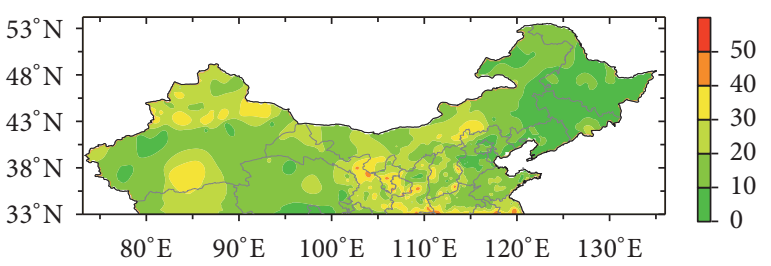

(d) Maximum SI 4-SI 2

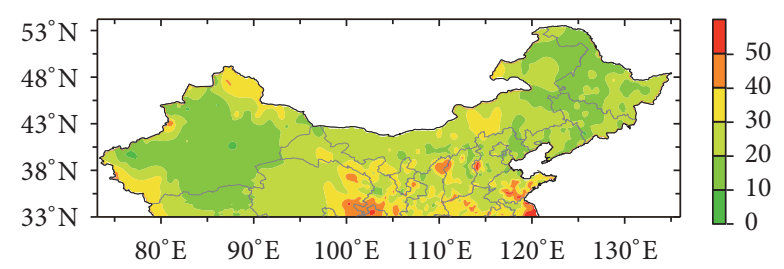

(f) Maximum SI 2-SI 1

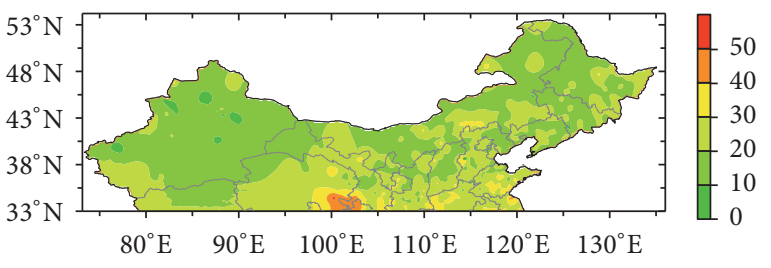

(h) Maximum SI 4-SI 3

FIGURE 3: Differences (days) in the start of the growing season between selected indices in northern China. Shown are the mean values ((a), (c), (e), and (g)) and maximum values ((b), (d), (f), and (h)).

2.0-6.5 days (Figure $3(\mathrm{~g})$ ). The maximum differences for SI 3 versus SI 4 were smaller in the northwestern, northern, and northeastern parts of the study area, with the mean values of $0-20$ days at most stations, but larger in the southern part, with the mean values of 20-50 days at most stations (Figure 3(h)).

\subsection{Indices for the End of the Growing Season}

3.2.1. Regional Average of Correlation for Combinations of Indices. The mean correlation coefficients among combinations of indices of the growing season end ranged from 0.63 to 0.88 (Table 3). The maximum correlation coefficients ranged from 0.94 to 1.00 , and the minimum correlation coefficients ranged from 0.21 to 0.55 . These ranges are smaller than those of the start indices of the growing season, indicating a less homogenous pattern in northern China. Out of the five indices, the combination of EI 4 and EI 5 showed the highest correlation $(r=0.88)$, indicating a high common variability between those two indices. Higher correlations were also found when indices which did not consider frost were compared with indices including the frost criteria and both had the same length of the spells (e.g., mean correlation was 0.87 at EI 1 versus EI 4). Weaker correlations occurred when EI $3\left(10 \mathrm{~d}<5^{\circ} \mathrm{C}\right)$ was included in the combinations (mean correlation coefficients ranged from 0.63 to 0.73 , maximum coefficients ranged from 0.94 to 0.96 , and minimum coefficients ranged from 0.21 to 0.36 ), for the length of the spells exceeding the threshold had larger differences among EI 3 and other end indices. Except for EI 3, the correlation coefficients were medium when only the length of the spells exceeding the threshold was different (e.g., mean correlation coefficient was equal to 0.82 at EI 1 versus EI 2). The weaker correlations were also found when the length of the spells exceeding the threshold was different and one of the indices included the frost criteria (e.g., mean correlation coefficient was equal to 0.71 at EI 2 versus EI 4 and was 0.74 at EI 1 versus EI 5).

\subsubsection{Spatial Distribution of Correlation for Combinations} of Indices. The correlations between indices of the growing season end were different from those of the start indices and had large spatial difference, but they were also significant at 
TABLE 3: Correlation coefficients for combinations of the end indices of growing season. Single bold values show the mean coefficients over northern China, and the paired values below show the minimum (left) and maximum (right) coefficients.

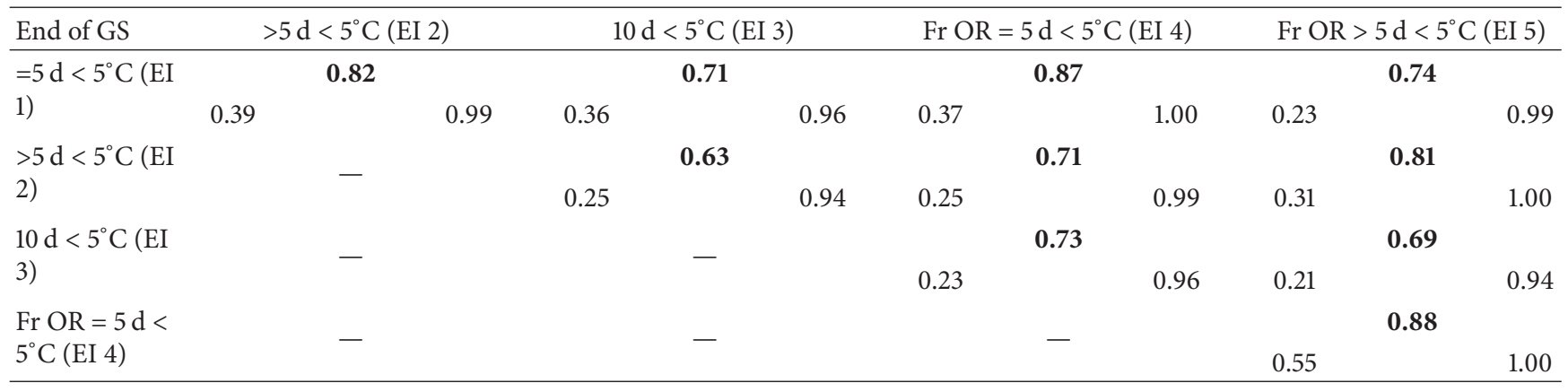

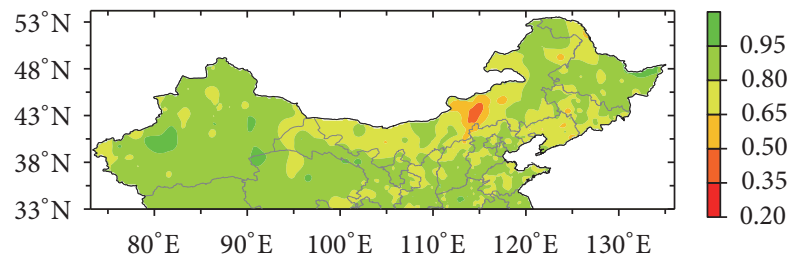

(a) EI 1 versus EI 2

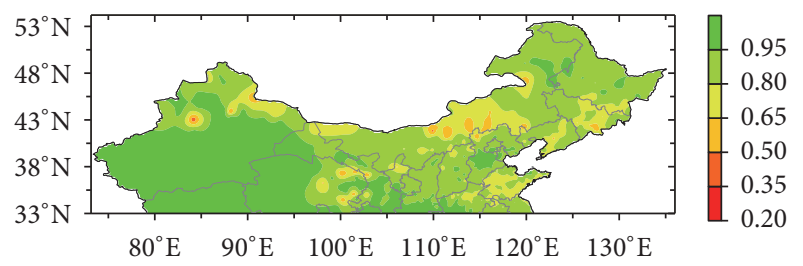

(c) EI 1 versus EI 4

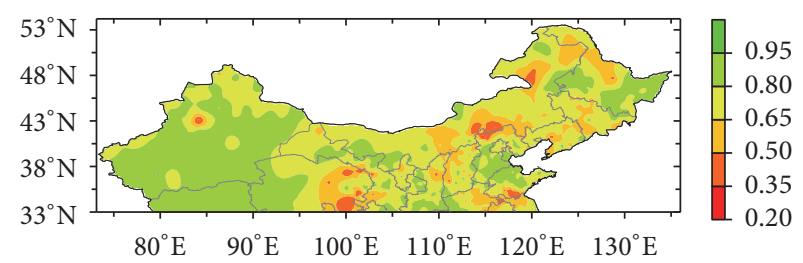

(e) EI 3 versus EI 4

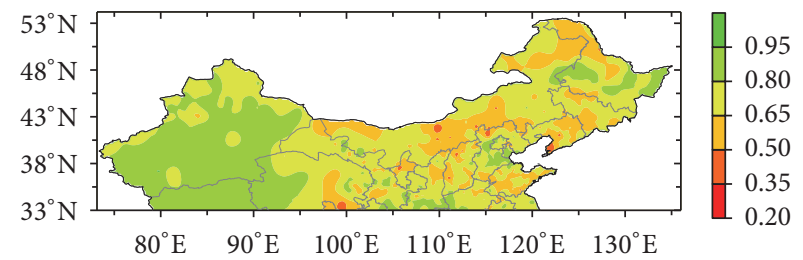

(b) EI 1 versus EI 3

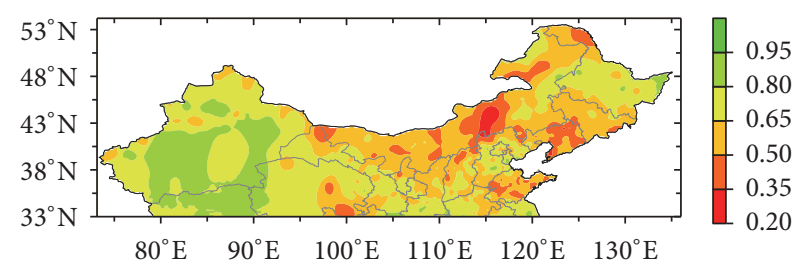

(d) EI 2 versus EI 3

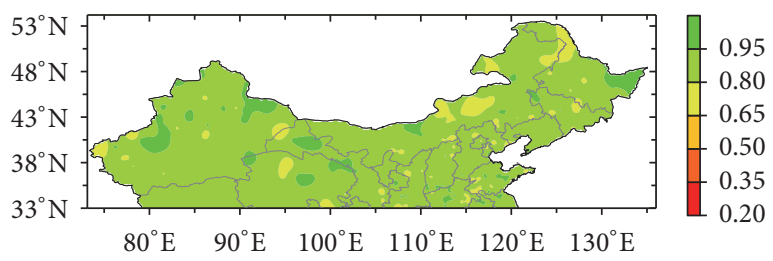

(f) EI 4 versus EI 5

FIGURE 4: Correlation coefficients for combinations of the end indices of growing season in northern China.

the 0.01 level in almost all areas of northern China. Stations with higher correlation coefficients among combinations of indices were mostly located in the western part of the study area, whereas in the eastern and northeastern part, there was no constant and strong relationship between different indices (Figure 4). Except for two stations (Abag Banner station and Bordered Yellow Banner station) in Inner Mongolia, the correlation coefficients for the combination of EI 1 and EI 2 were all over 0.50 , and in most areas they ranged from 0.65 to 0.95 , accounting for $92.5 \%$ of the total stations across northern China (Figure 4(a)). For the combination of EI 1 and EI 3, there were obvious differences in correlation coefficients between the western and the eastern regions. In the Inner Mongolia, Gansu, central and eastern Qinghai, and the east of above regions, $75.9 \%$ of the total stations had the correlation coefficients of $0.50-0.80$, but in central and southern
Xinjiang, northern Tibet, and western Qinghai, most stations had correlation coefficients of $0.80-0.95$ (Figure 4(b)).

The correlation coefficients for EI 1 versus EI 4 were higher as a whole, and in most areas they ranged from 0.65 to 1.00 , accounting for $96.0 \%$ of the total stations across northern China; especially in central and southern Xinjiang, northern Tibet, western Qinghai, and some areas of Gansu, Shaanxi, Hebei, Inner Mongolia, and other provinces, they were over 0.95 at most stations (Figure $4(\mathrm{c})$ ). The spatial pattern of correlation coefficients for EI 2 versus EI 5 was basically similar to that of EI 1 versus EI 4 . The correlation coefficients for EI 2 versus EI 3 were lower as a whole, and at $90.7 \%$ of the total stations they were between 0.35 and 0.80 ; especially in western and central Inner Mongolia, northern Shaanxi and Shanxi, Shandong, Liaoning, Jilin, northern Heilongjiang, and some areas of Qinghai, Hebei, and Gansu, 
TABLE 4: Correlation coefficients for combinations of indices of growing season length. Single bold values show the mean coefficient over northern China, and the paired values below show the minimum (left) and maximum (right) coefficients.

\begin{tabular}{|c|c|c|c|c|c|c|c|c|c|c|}
\hline Length of GS & \multicolumn{2}{|c|}{ SI $2 \mid$ EI 2 (LI 2) } & \multicolumn{2}{|c|}{ SI $3 \mid$ EI 3 (LI 3) } & \multicolumn{2}{|c|}{ SI $4 \mid$ EI 3 (LI 4) } & \multicolumn{2}{|c|}{ SI $3 \mid$ EI 4 (LI 5) } & \multicolumn{2}{|c|}{ SI $4 \mid$ EI 5 (LI 6) } \\
\hline \multirow{2}{*}{ SI $1 \mid$ EI 1 (LI 1) } & \multicolumn{2}{|c|}{0.84} & \multicolumn{2}{|c|}{0.83} & \multicolumn{2}{|c|}{0.77} & \multicolumn{2}{|c|}{0.89} & \multicolumn{2}{|c|}{0.77} \\
\hline & 0.64 & 0.97 & 0.48 & 0.97 & 0.37 & 0.96 & 0.34 & 1.00 & 0.32 & 0.95 \\
\hline \multirow{2}{*}{ SI 2 | EI 2 (LI 2) } & \multirow{2}{*}{\multicolumn{2}{|c|}{-}} & & & \multicolumn{2}{|c|}{0.83} & \multicolumn{2}{|c|}{0.76} & \multicolumn{2}{|c|}{0.88} \\
\hline & & & 0.38 & 0.93 & 0.51 & 0.96 & 0.31 & 0.95 & 0.40 & 1.00 \\
\hline \multirow{2}{*}{ SI 3 | EI 3 (LI 3) } & \multirow{2}{*}{\multicolumn{2}{|c|}{ - }} & \multirow{2}{*}{\multicolumn{2}{|c|}{ - }} & & & \multicolumn{2}{|c|}{0.90} & \multicolumn{2}{|c|}{0.81} \\
\hline & & & & & 0.74 & 1.00 & 0.54 & 0.98 & 0.40 & 0.97 \\
\hline \multirow{2}{*}{ SI 4 | EI 3 (LI 4) } & \multirow{2}{*}{\multicolumn{2}{|c|}{ - }} & \multirow{2}{*}{\multicolumn{2}{|c|}{ - }} & \multirow{2}{*}{\multicolumn{2}{|c|}{ - }} & & & \multicolumn{2}{|c|}{0.88} \\
\hline & & & & & & & 0.49 & 0.97 & 0.56 & 0.98 \\
\hline \multirow{2}{*}{ SI 3 | EI 4 (LI 5) } & \multirow{2}{*}{\multicolumn{2}{|c|}{-}} & \multirow{2}{*}{\multicolumn{2}{|c|}{-}} & \multirow{2}{*}{\multicolumn{2}{|c|}{ - }} & \multirow{2}{*}{\multicolumn{2}{|c|}{ - }} & \multicolumn{2}{|c|}{0.89} \\
\hline & & & & & & & & & 0.65 & 0.99 \\
\hline
\end{tabular}

they were lower than 0.65 in most areas, accounting for $51.3 \%$ of the total stations (Figure $4(\mathrm{~d})$ ). Only in some areas in Xinjiang, northern Tibet, and western Qinghai, correlation coefficients were over 0.80 .

For the combination of EI 3 and EI 4, correlation coefficients mainly ranged from 0.50 to 0.80 in northern Xinjiang, western Inner Mongolia, eastern Qinghai, and some areas in the northeastern and eastern parts of the study area, accounting for $64.5 \%$ of the total stations, but in central and southern Xinjiang, northern Tibet, western Qinghai, and some areas of Gansu, Shaanxi, Hebei, Inner Mongolia, and Heilongjiang, they were over 0.80 in most areas, accounting for $30.8 \%$ of the total stations (Figure 4(e)). Similar spatial patterns in correlation coefficients also existed at EI 1 versus EI 5, EI 2 versus EI 4, and EI 3 versus EI 5. The correlation coefficients for EI 4 versus EI 5 were also higher and all of them were over 0.65 (Figure $4(\mathrm{f})$ ). At $75.7 \%$ of the total stations, they were between 0.80 and 0.95 .

3.2.3. Spatial Distribution of Difference for Combinations of Indices. The differences in the end of the growing season were also spatially differentiated in northern China, with smaller mean and maximum differences in the western and northeastern parts and larger values in the central and eastern parts of the study area (Figure 5). For the two combinations of EI 1 and EI 4 and EI 2 and EI 5, smaller differences were observed in most of the study area, with the mean values of $0-3.0$ days and the maximum values of $0-30$ days at most stations (Figures 5(a)-5(d)). Except for dozens of stations mainly distributed in the central Inner Mongolia, northwestern Hebei, southern and central Liaoning, and central and southeastern Jilin, the differences for these two combinations were statistically insignificant. Thus, the additional consideration of first autumn/winter frost in EI 4 and EI 5 did not make them much different from EI 1 and EI 2. Taking the frost criterion into account in the end of the growing season is also less important for most parts of the northern China.

Compared with above indices, the end of the growing season produced by EI 3 was systematically earlier (Figures 5(e)-5(f)). This is due to the difference in the length of the spells exceeding the threshold. Here the 10-day-running mean instead of 5- or 6-day spells was used to establish the EI 3 index. For the combination of EI 1 and EI 3, larger differences mainly occurred in southern and northwestern Heilongjiang, Jilin, Liaoning, Shandong, Henan, southeastern Qinghai, most of Inner Mongolia, Shanxi, and Hebei and some areas of Shaanxi, Gansu, and Ningxia, with the mean values of 7.5-9.0 days and the maximum values of 24-40 days at most stations (Figures 5(e)-5(f)). The mean differences for EI 2 versus EI 3 were larger as a whole, ranging from 6.0 to 12.0 days at most stations; especially in some areas of east-central Inner Mongolia, southern Jilin, and eastern Liaoning, they were over 10.5 days (Figure 5(g)). The maximum differences for EI 2 versus EI 3 also ranged from 16.0 to 40.0 days at most stations, with larger values in Henan and Shandong and smaller values in most of southern Xinjiang, northern Tibet, and north-central Heilongjiang (Figure 5(h)). For the combinations of EI 1 and EI 3 and EI 2 and EI 3, the differences were all statistically significant at all stations.

For the combination of EI 1 and EI 2, larger mean differences were mainly distributed in the eastern, northeastern, and some northwestern parts of the study area, with the mean of 1.6-3.2 days at most stations, and the differences were statistically insignificant at all stations except for several stations (Figure 5(i)). The larger maximum differences with the values of 14-28 days were distributed in the majority of the study area (Figure 5(j)). The mean differences for EI 4 versus EI 5 were smaller as a whole, ranging from 0 to 1.6 days at most stations, and the differences were statistically insignificant at all stations (Figure 5(k)). The maximum differences for EI 4 versus EI 5 ranged from 7 to 28 days at most stations (Figure 5(l)).

\subsection{Indices for the Length of the Growing Season}

3.3.1. Regional Average of Correlation for Combinations of Indices. The correlations among six indices of the growing season length are shown in Table 4 . The mean correlation coefficients among combinations of indices ranged from 0.74 to 0.92 . The maximum correlation coefficients ranged from 0.93 to 1.00 , and the minimum correlation coefficients ranged from 0.31 to 0.74 . These ranges are also lower than the 


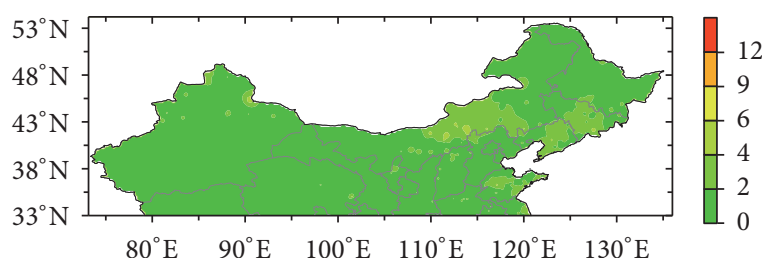

(a) Mean EI 1-EI 4

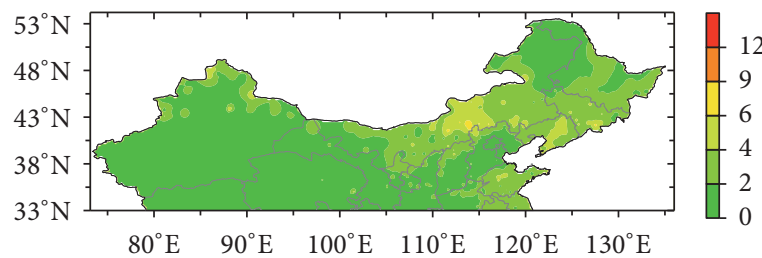

(c) Mean EI 2-EI 5

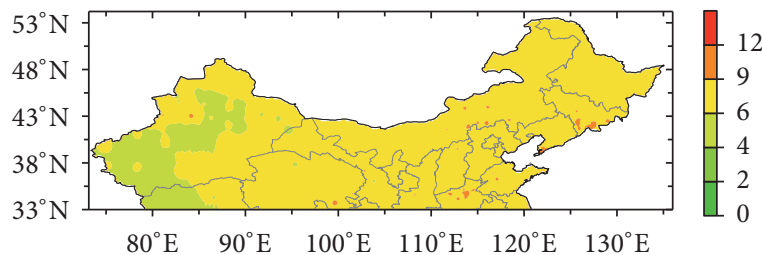

(e) Mean EI 1-EI 3

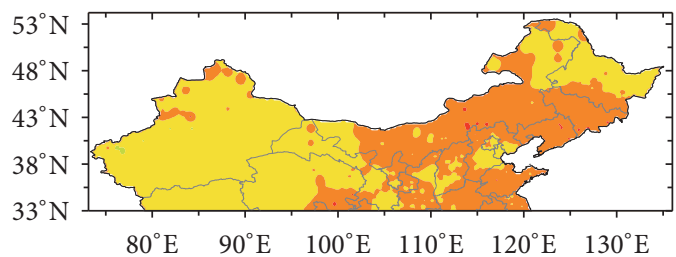

(g) Mean EI 2-EI 3

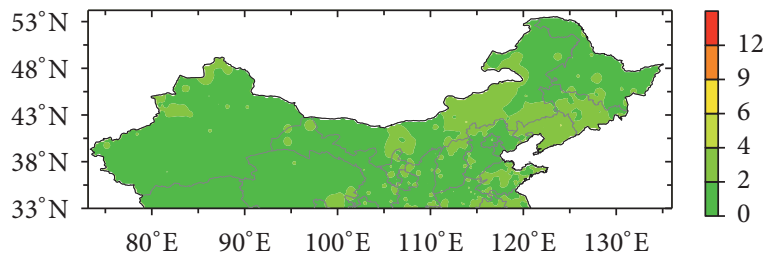

(i) Mean EI 2-EI 1

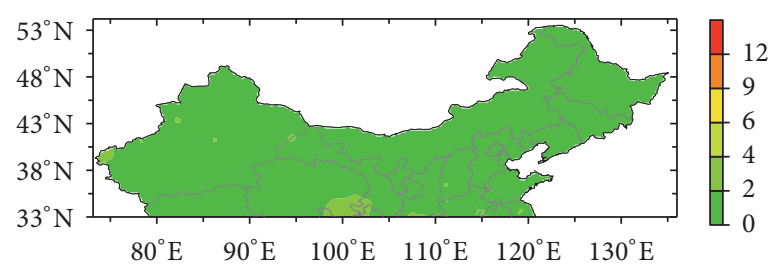

(k) Mean EI 5-EI 4

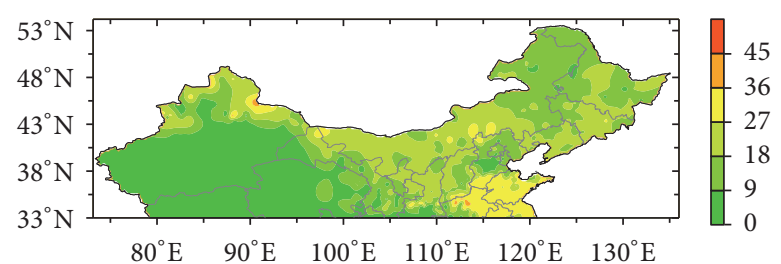

(b) Maximum EI 1-EI 4

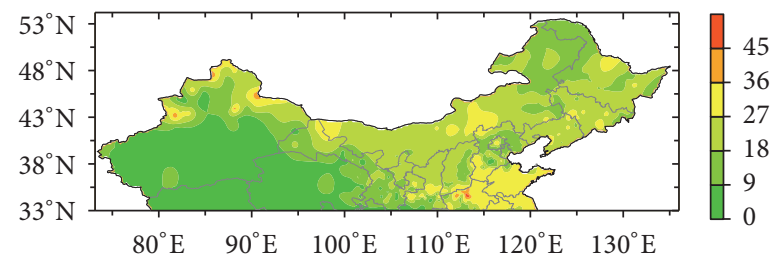

(d) Maximum EI 2-EI 5

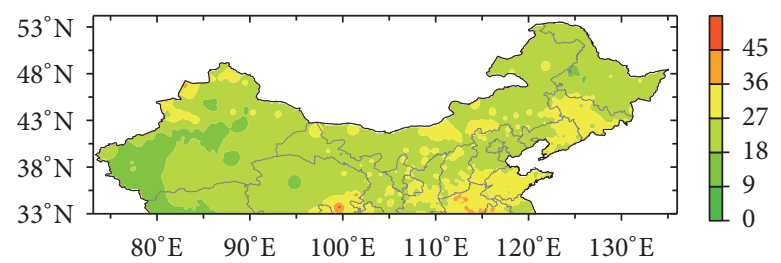

(f) Maximum EI 1-EI 3

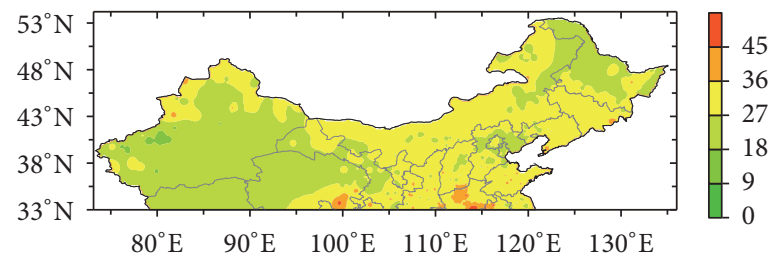

(h) Maximum EI 2-EI 3

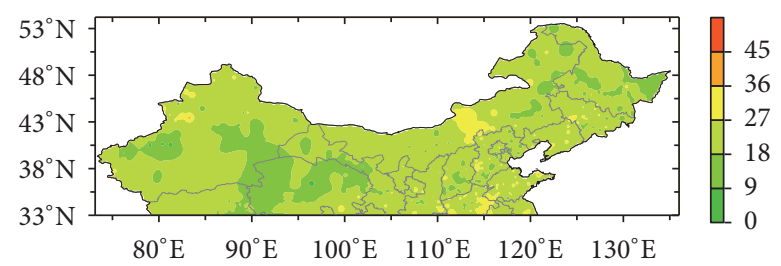

(j) Maximum EI 2-EI 1

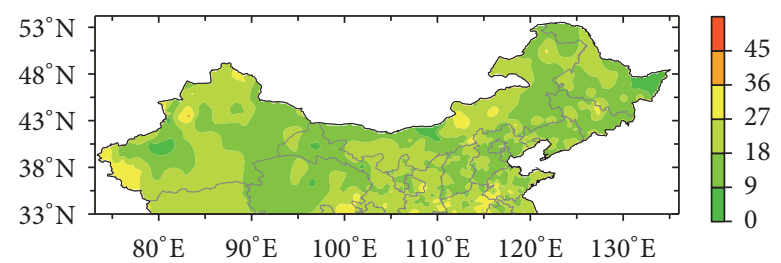

(l) Maximum EI 5-EI 4

FIGURE 5: Differences (days) in the end of the growing season between selected indices in northern China. Shown are the mean values ((a), (c), (e), (g), (i), and (k)) and maximum values ((b), (d), (f), (h), (j), and (l)).

correlation coefficients for combinations of start indices, but higher than those for combinations of end indices. Out of the six indices, the combination of LI 3 and LI 4 showed the highest correlation coefficient, indicating a high common variability between two indices, which is related to the little differences in the indices of SI 3 versus SI 4 . The correlation coefficients for pairwise combinations of LI 3, LI 4, and LI 5 indices were all beyond 0.81 , suggesting a more homogenous pattern of LI 3, LI 4, and LI 5 in northern China. The lowest mean correlation coefficient $(r=0.74)$ was found in the combination of LI 2 and LI 3, which is in line with the results at EI 2 versus EI 3. 


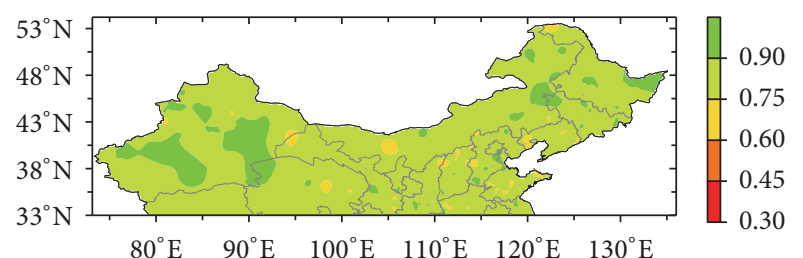

(a) LI 1 versus LI 2

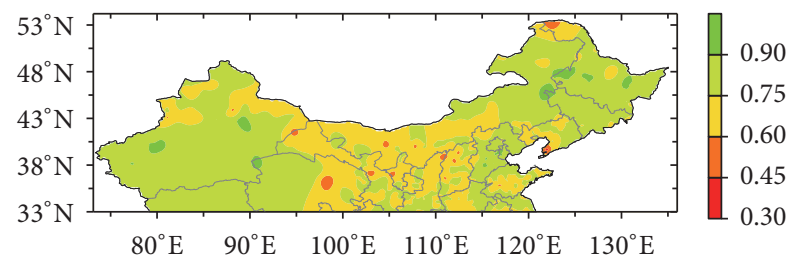

(c) LI 1 versus LI 4

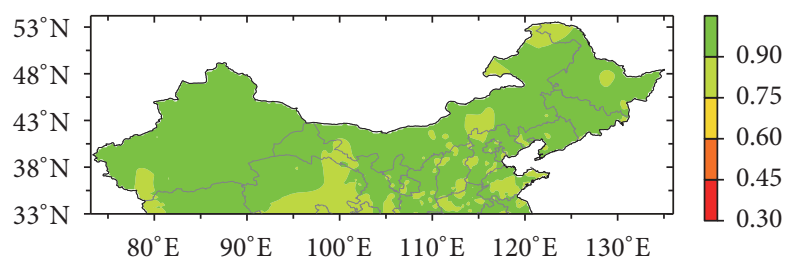

(e) LI 3 versus LI 4

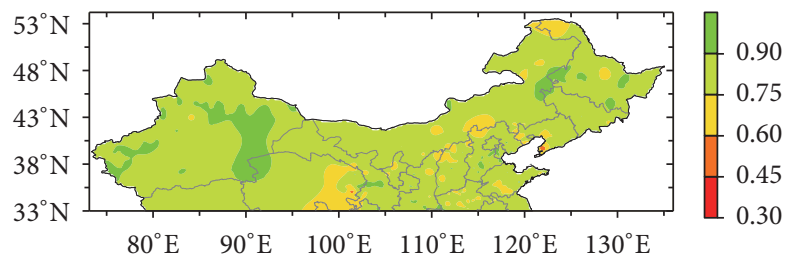

(g) LI 4 versus LI 5

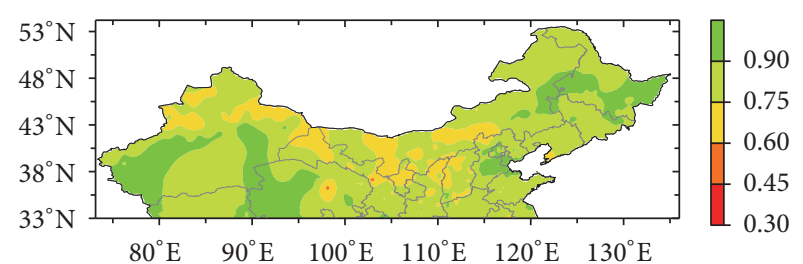

(b) LI 1 versus LI 3

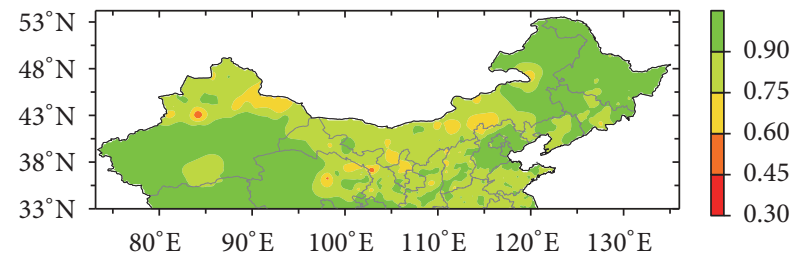

(d) LI 1 versus LI 5

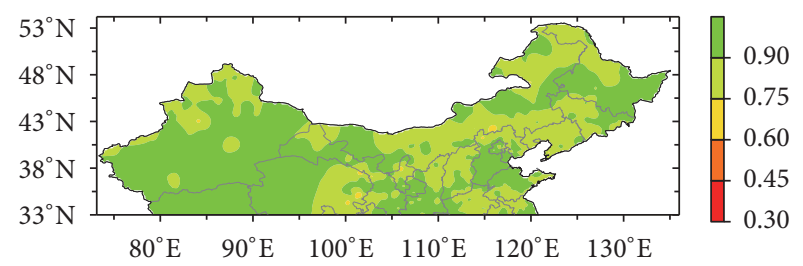

(f) LI 3 versus LI 5

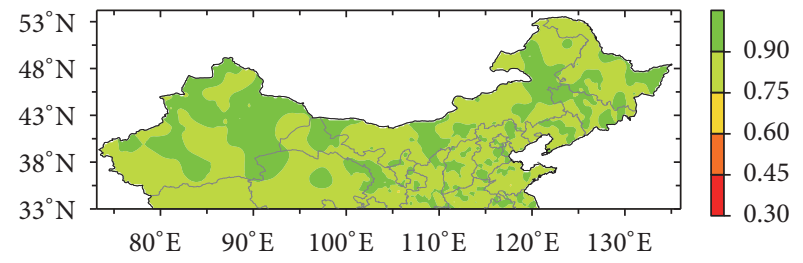

(h) LI 5 versus LI 6

FIGURE 6: Correlation coefficients for combinations of indices of growing season length in northern China.

3.3.2. Spatial Distribution of Correlation for Combinations of Indices. The correlations between indices of the growing season length were generally higher and statistically significant in the whole study area; especially in the majority of the western and northeastern parts, they were mainly over 0.75 , and the spatial differences were less than those of the start and end indices (Figure 6). The spatial distribution of correlation coefficients for the combination of LI 1 and LI 2 was comparatively consistent (Figure 6(a)). At all stations the correlation coefficients were over 0.60 , and at $92.4 \%$ of the total stations they were between 0.75 and 0.97 . There were $82.0 \%$ of the total stations with correlation coefficients of $0.60-0.90$ at LI 1 versus LI 3 (Figure 6(b)). In some areas in Xinjiang, southwestern Qinghai, Heilongjiang, eastern Inner Mongolia, and Hebei, the correlation coefficients were over 0.90 , accounting for $16.8 \%$ of the total stations. A similar spatial pattern of correlation coefficients was also observed at LI 2 versus LI 4. The correlation coefficients for LI 1 versus LI 4 were lower as a whole, and there were $93.3 \%$ of the total stations with correlation coefficients of 0.60-0.90 (Figure 6(c)). Similar spatial patterns of correlation coefficients also existed at LI 1 versus LI 6, L2 versus L3, and LI 2 versus LI 5.
For combination of LI 1 and LI 5, there were 93.5\% of the total stations with correlation coefficients of over 0.75 (Figure 6(d)). In southern Xinjiang, northern Tibet, western Qinghai, Heilongjiang, eastern Inner Mongolia, western Jilin, and most of Hebei, correlation coefficients were mostly over 0.90 , accounting for $45.4 \%$ of the total stations. A similar spatial pattern of correlation coefficients occurred at LI 2 versus LI 6 . The correlation coefficients for combinations of LI 3 and LI 4 and LI 3 and LI 5 were higher as a whole, and at all stations they were over 0.75 and 0.60 , respectively (Figures 6(e)-6(f)). In these two combinations, stations with correlation coefficients of over 0.90 accounted for $74.3 \%$ and $49.0 \%$ of the total stations, respectively. The correlation coefficients for LI 4 versus LI 6 were basically similar to those of LI 3 versus LI 5. For the combination of LI 4 and LI 5, the correlation coefficients were also relatively consistent, and there were $77.5 \%$ of the total stations with correlation coefficients of $0.75-0.90$ (Figure 6(g)). A similar spatial pattern in correlation coefficients was also found at LI 3 versus LI 6. The correlation coefficients at almost all of the stations $(99.0 \%)$ were $0.75-0.99$ for the combination of LI 5 and LI 6 , and their spatial distributions also had no obvious characteristics (Figure 6(h)). 


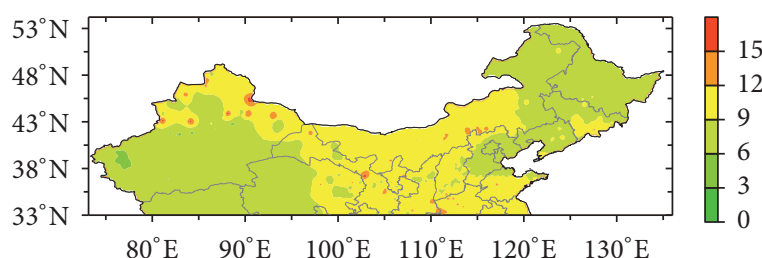

(a) Mean LI 1-LI 3

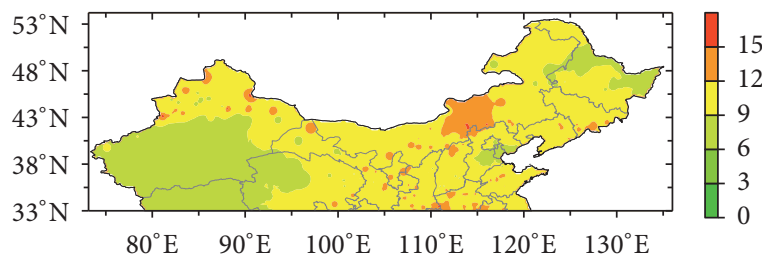

(c) Mean LI 2-LI 4

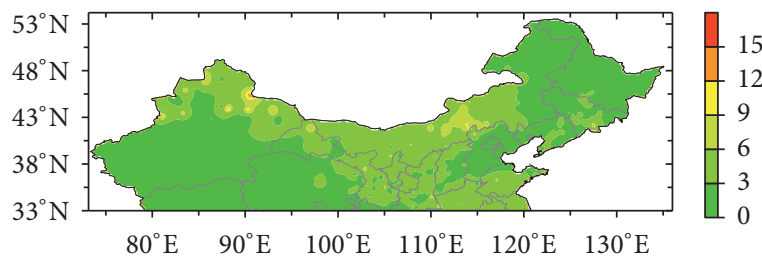

(e) Mean LI 1-LI 5

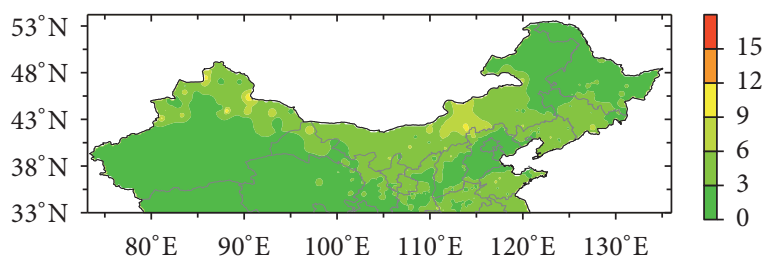

(g) Mean LI 2-LI 6

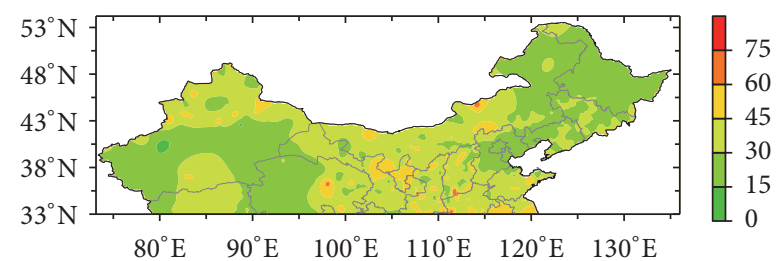

(b) Maximum LI 1-LI 3

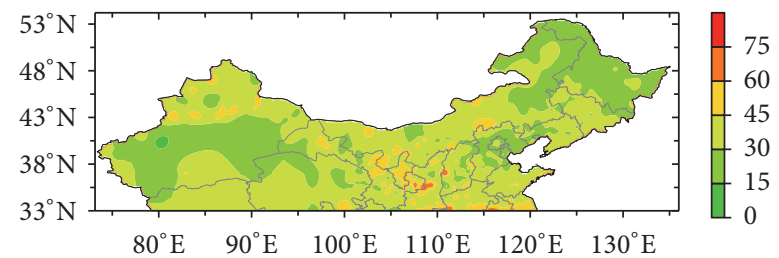

(d) Maximum LI 2-LI 4

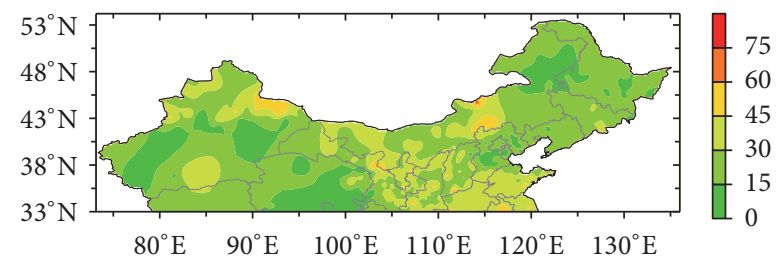

(f) Maximum LI 1-LI 5

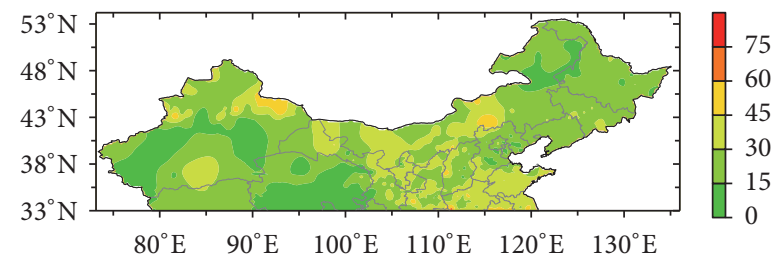

(h) Maximum LI 2-LI 6

Figure 7: Differences (days) in the length of the growing season between selected indices in northern China. Shown are the mean values ((a), (c), (e), and (g)) and maximum values ((b), (d), (f), and (h)).

3.3.3. Spatial Distribution of Difference for Combinations of Indices. The differences in the length of the growing season are displayed in Figure 7. Smaller mean and maximum differences were showed in the southwestern and northeastern parts, whereas larger values appeared in the eastern and northwestern parts of the study area (Figure 7). For the two combinations of LI 1 and LI 3 and LI 2 and LI 4, smaller mean differences were observed in the southwestern part and some northeastern part of the study area, with the mean values of 5.0-9.4 days at most stations, while larger mean differences were found in the northwestern and eastern parts, with the mean values of 9.4-13.8 days (Figures 7(a) and 7(c)). The differences for these two combinations were statistically significant at all stations. Similar spatial distributions also existed in the differences of the maximum values, with smaller differences of 12-36 days in most of the southwestern and northeastern parts, and larger values of 36-60 days in most of the northwestern and eastern parts of the study area (Figures 7(b) and 7(d)).

For combinations of LI 1 and LI 5 and LI 2 and LI 6, smaller differences were observed in most of the southwestern and northeastern parts of the study area, with the mean values of $0-5.0$ days and the maximum differences of $0-24$ days at most stations (Figures $7(\mathrm{e})-7(\mathrm{~h})$ ). In the eastern and northwestern parts of the study area, mean differences ranged from 2.5 to 7.5 days and the maximum differences ranged from 24 to 48 days at most stations. At some scattered stations in mid-eastern Inner Mongolia, northern Xinjiang, Shaanxi, Shanxi, Henan, Jiangsu, and Anhui, mean differences were over 7.5 days or the maximum differences were over 48 days. Except for about 150 stations mainly distributed in the central Inner Mongolia, northern Shanxi, northwestern Hebei, western Gansu, northern Xinjiang, and southern and central Liaoning, the differences for these two combinations were statistically insignificant at all stations.

\section{Discussion}

Plant phenology is a sensitive and observable indicator of terrestrial ecosystem response to climate change and has attracted increasing attention in the past few decades in the context of global change $[17,18]$. The timing and length of growing season are important for agricultural production, ecological security, and human activities $[3,13,19]$. Both 
observations and model simulations show a decrease in the number of frost days and an increase in the length of the growing season in the second half of the twentieth century [1]. Based on established indices, as well as new and modified indices of the start, end, and length of the growing season, the different indices used for calculating the thermal growing season were evaluated in the northern China. Larger differences and lower correlations between the indices in the eastern and northwestern parts and smaller differences and higher correlations in the southwestern and northeastern parts were observed in most combinations of the start, end, and length indices of the growing season over northern China (Figures 2-7), so the study area can be divided into two parts, the southwestern and northeastern regions with lower spatial variability in contrast to the eastern and northwestern regions with higher spatial variability.

In the central and eastern parts of the study area, there were larger differences in the timing and length of the growing season generally (Figures 3, 5, and 7), so the choice of the definition for the growing season parameters had important effects. The obvious spatial heterogeneity of the thermal growing season in these areas probably relates to the impacts of urbanization and high-intensity human activities on the local climate $[20,21]$. Based on time series NDVI images from 2001 to 2006, Liu et al. [22] found that, in the urban area of Beijing, vegetation had earlier start, later end, and longer length of the growing season, but in Tianjin and Tangshan, the urbanization caused later start, earlier end, and shorter length of the growing season. Hou and Yan [23] indicated that the start of the growing season for grassland was correlated strongly with March temperature in eastern China, but that for irrigated cropland was greatly affected by the February temperature during 1982-2006. Therefore, the analysis of thermal growing season characteristics with a single index may be incorrect in these regions, and it is important to compare the different definitions of the growing season parameters with the phenological observation and remote sensing monitoring.

In the northeastern part of the study area, the correlations between indices were higher and the differences were lower (Figures 2-7), so the definition of the growing season parameters had less influence on the timing and length of the growing season. However, in the western part of northern China, especially in the northwestern region, both the correlations and the differences between indices were unstable (Figures 2-7). Lower density of surface observation networks, higher altitudes and complex and diverse natural environments, and vegetation types might be responsible for the inconsistent distributions. Ding et al. [2] analyzed the relationship between the start of the growing season and temperature and precipitation over the Tibetan Plateau and found regions with significant delay for the start of the growing season were mostly distributed in the semi-arid areas, while regions with significant advance of the start were mainly scattered in humid and semi-humid areas from 1982 to 2012. In relatively humid area, the start of the growing season was significantly correlated with spring temperature, and the importance of spring temperature gradually decreased with increasing aridity. The results from $\mathrm{Ma}$ et al. [24] also indicated that different vegetation cover types in arid zone of Central Asia and Xinjiang, China, showed remarkably different patterns in phenological changes, and vegetation phenology varied obviously in different elevations.

Over northern China, the occurrence of the last spring frost (daily mean temperature less than $0^{\circ} \mathrm{C}$ ) generally preceded the first 5- or 6-day spell with daily mean temperature remaining above the $5^{\circ} \mathrm{C}$ threshold (Figure 8), and the first autumn/winter frost usually occurred later than the first 5- or 6-day spell with daily mean temperature remaining below $5^{\circ} \mathrm{C}$ (Figure 9). Averagely, the start date defined by nonfrost indices was later than the last spring frost date about 5-20 days, and the end date defined by nonfrost indices was earlier than the first autumn/winter frost date of 0-20 days in most of the northern China during 1961-2015. In this context, the frost criterion is less significant for the statistical analysis of the start and end of the growing season in northern China. This is consistent with existing results. For example, Li et al. [25] showed that there was no significant correlation between the end date of the growing season and the first autumn/winter frost date in northeast China during 1990-2010. In the Greater Baltic Area, Walther and Linderholm [9] also found that autumn frost did not have significant impacts on the end of the growing season.

However, some studies indicated that including the frost criterion or not in the definition of the start of the growing season could cause large differences. This is inconsistent with our results. For example, Walther and Linderholm [9] found that including or excluding the last spring frost criteria in the definitions had important effects on the start of the growing season in the western maritime stations of the Greater Baltic Area. Using meteorological data recorded at 47 meteorological stations over the year 1961-2010, Guo et al. [15] also showed that frost criterion had pronounced effects on the trends of growing season in central Inner Mongolia, especially on the start of the growing season. Considering that the maximum differences between indices including and excluding the frost criterion were comparatively large in northern China, though the mean differences are relatively small (Figures 3, 5, and 7), it is reasonable to consider the frost criterion in the definitions for determining the annual onset date and the length of the growing season at stations or in small regions.

Biological and environmental factors are the main factors influencing the plant growth, especially air temperature, photoperiod, and water [26]. The thermal growing season is broadly defined, and it does not really represent the actual biological growing season [13]. The phenological data from field observations are true and accurate for they are the integration of all relevant environmental factors which affect the growth of plants in a particular region, but the stations of phenological observation and historical phenological data are relatively scarce in China. Therefore, the best options to detect the variations in the growing season are the combination of limited phenological data and satellite data. Vegetation index has become a new way to monitor vegetation phenology [27], and the applicability of normalized difference vegetation index (NDVI) to obtain information about the plant phenology has been investigated in many studies. 


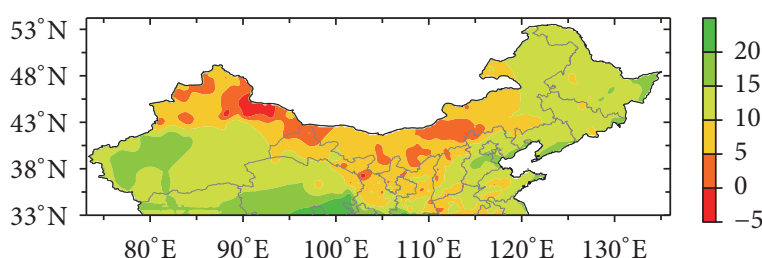

(a) SI 1-LSF

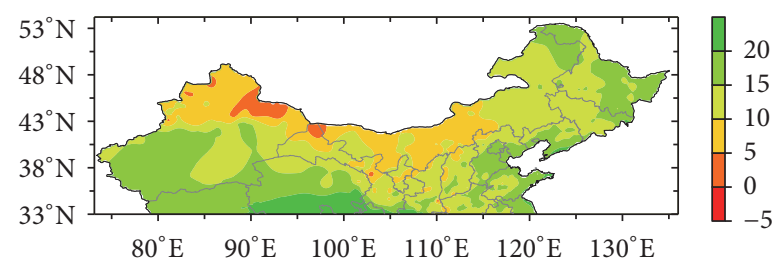

(b) SI 2-LSF

FIGURE 8: Average differences (days) in the start of the growing season between SI 1, SI 2, and the last spring frost (LSF) date in northern China during 1961-2015.

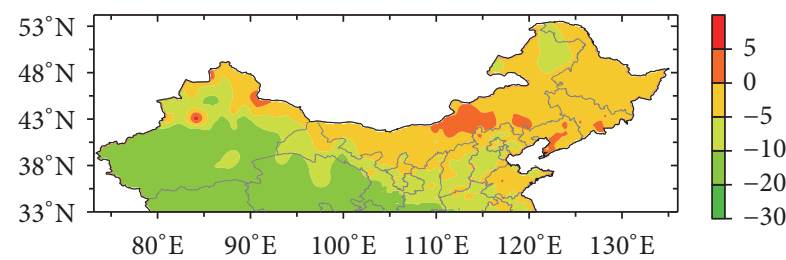

(a) EI 1-FAF

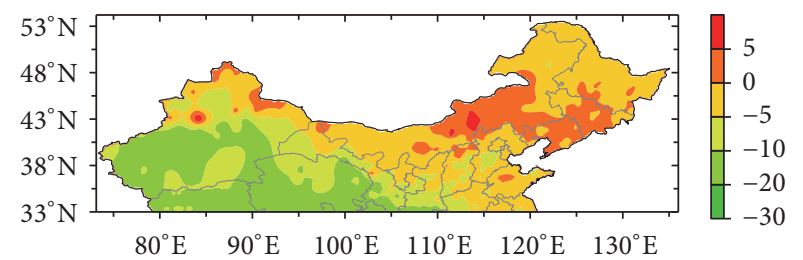

(b) EI 2-FAF

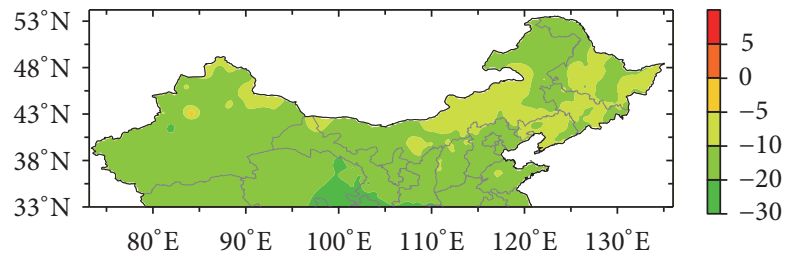

(c) EI 3-FAF

FIGURE 9: Average differences (days) in the end of the growing season between EI 1, EI 2, EI 3, and the first autumn/winter frost (FAF) date in northern China during 1961-2015.

Li et al. [25] showed that there were notable correlations between the observed cropland phenological period and the extracted length of the growing season from SPOT-VGT NDVI data in northeast China during 1990-2010. Hou et al. [17] also indicated that the extracted forest phenology using remote sensing is close to the records in situ measurements in northeastern China, so the forest phenophases obtained from SPOT-VGT NDVI dataset are feasible. Further studies include an integrated application of the climate data, phenological data, and remote sensing monitoring data of long-time series and high quality, with improved indices and methods suitable to local plant characteristics, to analyze the variations or trends in the growing season under the background of climate change.

\section{Conclusions}

Over northern China, higher correlation coefficients were found when indices without regard for frost were compared with those including the frost criteria and both had the same length of the spells exceeding the $5^{\circ} \mathrm{C}$ temperature threshold, and lower correlations were observed when the length of indices was different and one of the indices included the frost criteria or EI $3\left(10 \mathrm{~d}<5^{\circ} \mathrm{C}\right)$ was included in the combinations.
Including the frost criterion or not in the definitions of the start, end, and the length of the growing season could provide smaller mean differences than the differences from the length of the spells exceeding $5^{\circ} \mathrm{C}$ temperature threshold, but the maximum differences were large. So the consideration of spring/autumn frost is important for determining the annual timing and length of the growing season regarding the maximum differences.

The correlations and differences of the growing season indices were spatially differentiated. Larger differences and lower correlations were generally found in the eastern and northwestern parts and smaller differences and higher correlations were observed in the northeastern and southwestern parts of the study area, so the northern China can be divided into an eastern and northwestern part and a northeastern and southwestern part according to the growing season variability. In the eastern and northwestern parts of the study area, growing season was more sensitive to the changes in index definitions, and it is important to compare the local applicability of different definitions according to the phenological observation and remote sensing monitoring. In the northeastern and southwestern parts, less difference in the growing season indices was observed, so the choice of definitions had less influences on the growing season characteristics. 


\section{Conflicts of Interest}

The authors declare that they have no conflicts of interest.

\section{Acknowledgments}

This work was supported by National Natural Science Foundation of China (nos. 41571044 and 41001283), Climate Change Special Fund of the China Meteorological Administration (CCSF201716), and China Clean Development Mechanism (CDM) Fund Project (no. 2012043). The authors thank Bowen Zhang and Peipei Wei, Ecological Technique and Engineering College, Shanghai Institute of Technology, Shanghai, China, for their contributions.

\section{References}

[1] IPCC, Climate Change 2013: The Physical Science Basis, Cambridge University Press, New York, NY, USA, 2013.

[2] M.-J. Ding, L.-H. Li, Y. Nie, Q. Chen, and Y.-L. Zhang, "Spatiotemporal variation of spring phenology in Tibetan Plateau and its linkage to climate change from 1982 to 2012," Journal of Mountain Science, vol. 13, no. 1, pp. 83-94, 2016.

[3] X. Yang, T. Yang, H. Liu, and M. G. Ghebrezgabher, "Vegetation variation in the north hemisphere under climate warming in the last 30 years," Arid Zone Research, vol. 33, no. 2, pp. 379-391, 2016.

[4] J. Barichivich, K. R. Briffa, R. B. Myneni et al., "Large-scale variations in the vegetation growing season and annual cycle of atmospheric $\mathrm{CO}_{2}$ at high northern latitudes from 1950 to 2011," Global Change Biology, vol. 19, no. 10, pp. 3167-3183, 2013.

[5] G. Mozafari and M. Torki, "A study of initial, final and growing season length in west of Iran," International Journal of Advanced Biological and Biomedical Research, vol. 3, no. 1, pp. 65-69, 2015.

[6] H. Ci, Q. Zhang, V. P. Singh, M. Xiao, and L. Liu, "Spatiotemporal properties of growing season indices during 1961-2010 and possible association with agroclimatological regionalization of dominant crops in Xinjiang, China," Meteorology and Atmospheric Physics, vol. 128, no. 4, pp. 513-524, 2016.

[7] Y. Guo, Y. Jiang, M. Dong et al., "Trends in the tree growing season throughout the Hebei and Shanxi mountainous region and Loess Plateau of North China from 1961 to 2013," Resources Science, vol. 38, no. 4, pp. 758-767, 2016.

[8] T. R. Carter, "Changes in the thermal growing season in Nordic countries during the past century and prospects for the future," Agricultural and Food Science in Finland, vol. 7, no. 2, pp. 161179, 1998.

[9] A. Walther and H. W. Linderholm, "A comparison of growing season indices for the Greater Baltic Area," International Journal of Biometeorology, vol. 51, no. 2, pp. 107-118, 2006.

[10] P. D. Jones, K. R. Briffa, T. J. Osborn, A. Moberg, and H. Bergström, "Relationships between circulation strength and the variability of growing-season and cold-season climate in northern and central Europe," Holocene, vol. 12, no. 12, pp. 643656, 2002.

[11] P. Frich, L. V. Alexander, P. Della-Marta et al., "Observed coherent changes in climatic extremes during the second half of the twentieth century," Climate Research, vol. 19, no. 3, pp. 193-212, 2002.
[12] Y. Song, H. W. Linderholm, D. Chen, and A. Walther, "Trends of the thermal growing season in China, 1951-2007," International Journal of Climatology, vol. 30, no. 1, pp. 33-43, 2010.

[13] H. W. Linderholm, "Growing season changes in the last century," Agricultural and Forest Meteorology, vol. 137, no. 1-2, pp. 1-14, 2006.

[14] X. Chen, "Relationships between growing seasons determined by trees' phenology and air temperature: the case of the Taunus Mountain area in central Germany," Acta Meteorologica Sinica, vol. 58, no. 6, pp. 726-737, 2000.

[15] L. Guo, S. Wu, D. Zhao, G. Leng, and Q. Zhang, "Change trends of growing season over Inner Mongolia in the past 50 years," Scientia Geographica Sinica, vol. 33, no. 4, pp. 505-512, 2013.

[16] P. D. Jones and K. R. Briffa, "Growing season temperatures over the former Soviet Union," International Journal of Climatology, vol. 15, no. 9, pp. 943-959, 1995.

[17] X.-H. Hou, Z. Niu, and S. Gao, "Phenology of forest vegetation in northeast of China in ten years using remote sensing," Spectroscopy and Spectral Analysis, vol. 34, no. 2, pp. 515-519, 2014.

[18] J. Zhai, F.-H. Yuan, and J.-B. Wu, "Research progress on vegetation phenological changes," Chinese Journal of Ecology, vol. 34, no. 11, pp. 3237-3243, 2015.

[19] H. Wang, G.-H. Liu, Z.-S. Li, X. Ye, M. Wang, and L. Gong, "Driving force and changing trends of vegetation phenology in the Loess Plateau of China from 2000 to 2010," Journal of Mountain Science, vol. 13, no. 5, pp. 844-856, 2016.

[20] X. Yang, Z. Tian, and B. Chen, "Thermal growing season trends in east China, with emphasis on urbanization effects," International Journal of Climatology, vol. 33, no. 10, pp. 24022412, 2013.

[21] P. Zhao, P. Jones, L. Cao et al., "Trend of surface air temperature in Eastern China and associated large-scale climate variability over the last 100 years," Journal of Climate, vol. 27, no. 12, pp. 4693-4703, 2014.

[22] J. Liu, H. Guo, L. Zhang, and L. Lu, "Impact of urbanization on vegetation phenology research in Beijing-Tianjin-Tangshan region," Remote Sensing Technology and Application, vol. 29, no. 2, pp. 286-292, 2014.

[23] M. Hou and X. Yan, "Detecting vegetation phenological changes in response to climate in eastern China," Advances in Meteorological Science and Technology, vol. 2, no. 4, pp. 39-47, 2012.

[24] Y. Ma, C. Zhang, and T. Tashpolat, "Spatial-temporal change of vegetation phenology in arid zone of central Asia and Xinjiang," Progressus Inquisitiones De Mutatione Climatis, vol. 10, no. 2, pp. 95-102, 2014.

[25] Z. Li, H. Tang, P. Yang et al., "Spatio-temporal responses of cropland phenophases to climate change in Northeast China," Journal of Geographical Sciences, vol. 22, no. 1, pp. 29-45, 2012.

[26] Y. Xu, P. Lu, and Q. Yu, "Review and prospect in the researches of influence of climate change on plant phenology," Resources Science, vol. 26, no. 1, pp. 129-136, 2004.

[27] Y. Yang, J. Tian, Y. Rong, and A. Long, "Monitoring spatial patterns of vegetation phenology in Heihe river basin based on remote sensing," Remote Sensing Technology and Application, vol. 27, no. 2, pp. 282-288, 2012. 

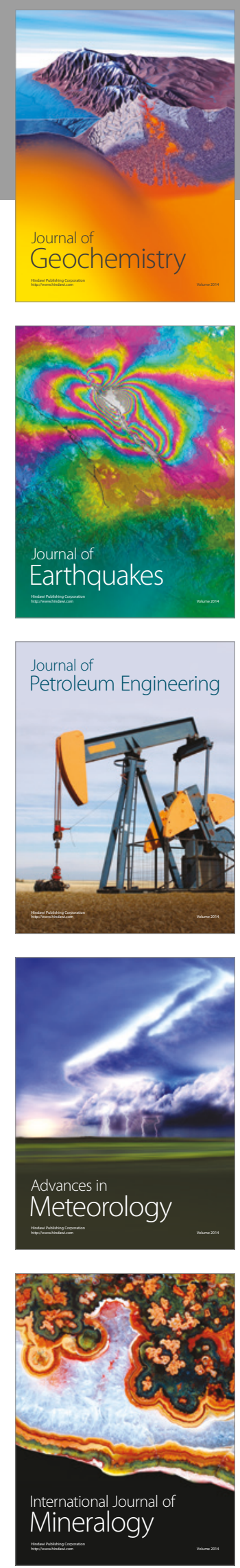
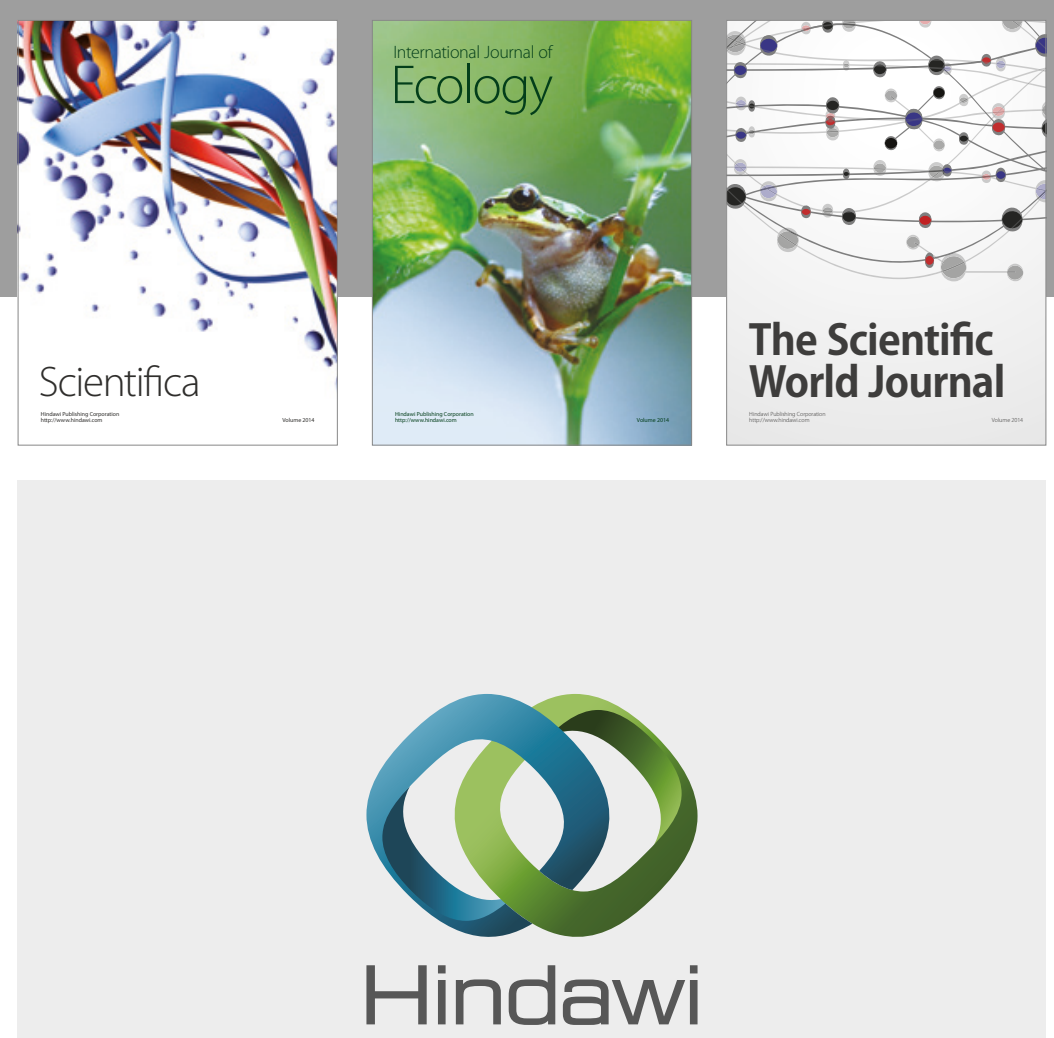

Submit your manuscripts at

https://www.hindawi.com
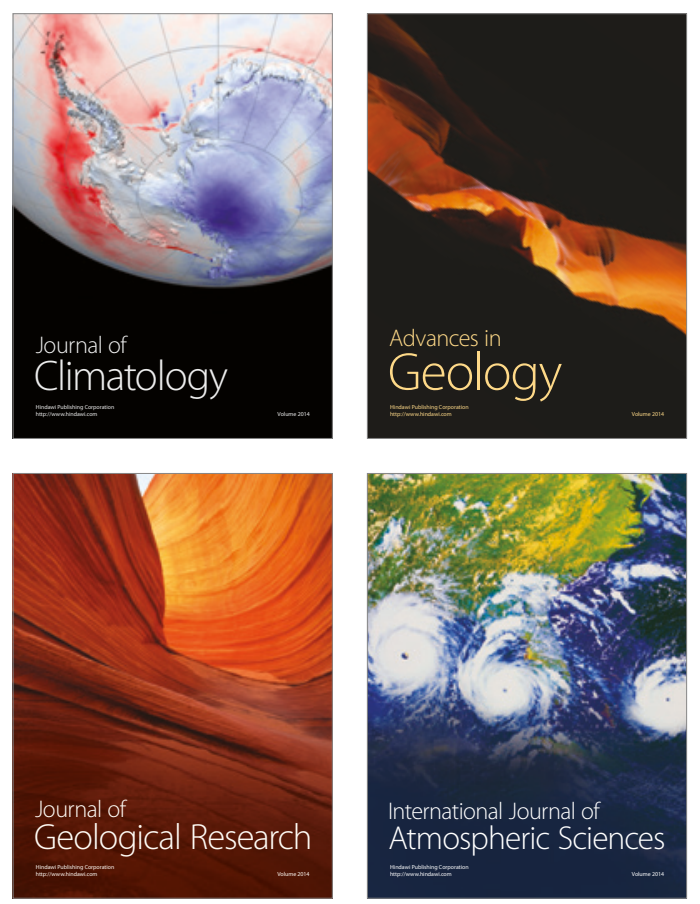

The Scientific

World Journal
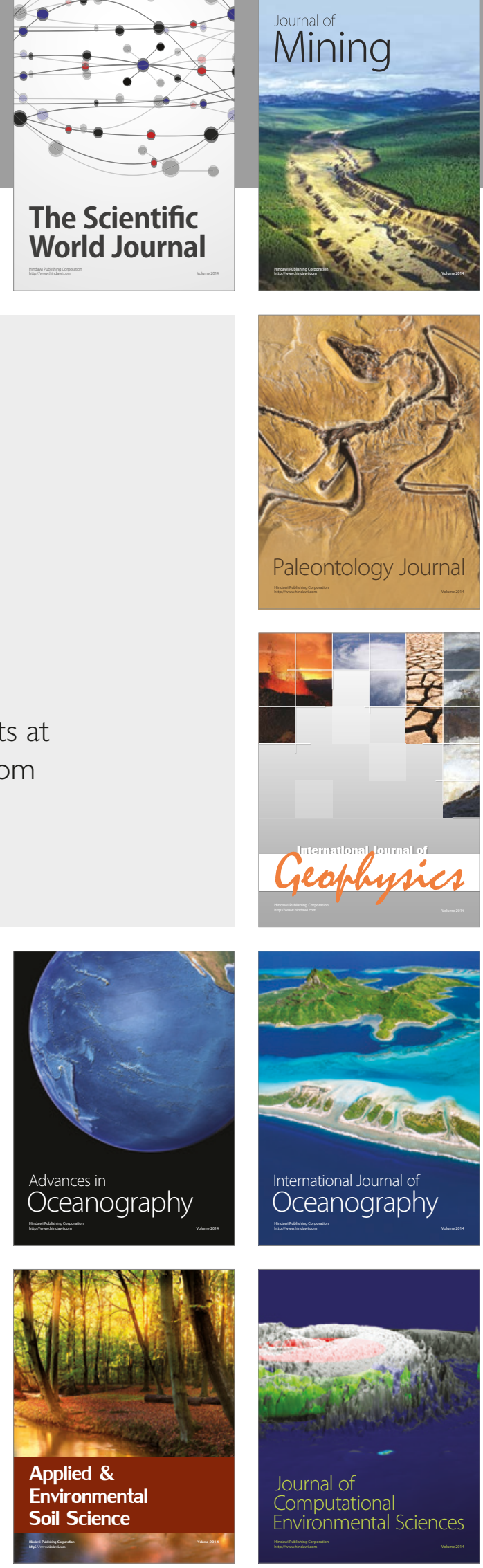